\title{
Developmental effects of Malathion exposure on locomotor activity and anxiety-like behavior in Wistar rat
}

\author{
Pacôme Kouadio N'Go ${ }^{1 *}$, Fatima-Zahra Azzaoui ${ }^{1}$, Ahmed Omar Touhami Ahami ${ }^{1}$, \\ Porlo Rigobert Soro ${ }^{1}$, Mohamed Najimi ${ }^{2}$, Fatiha Chigr $^{2}$ \\ ${ }^{1}$ Unit of Clinic and Cognitive Neuroscience, Laboratory of Biology and Health, Department of Biology, Faculty of Sciences, IBN \\ TOFAILUniversity, Kénitra, Morocco; ${ }^{*}$ Corresponding Author: ngopac@hotmail.fr \\ ${ }^{2}$ Laboratory of Animal Physiology, Department of Biology, Faculty of Sciences and Technology, Sultan Moulay Slimane University, \\ Béni Mellal, Morocco
}

Received 31 December 2012; revised 8 February 2013; accepted 22 February 2013

\section{ABSTRACT}

Developmental exposure to organophosphate insecticide is well known to induce neurobehavioral impairments, at late period. The present study aims to investigate the effects of chronic exposure to Malathion, from in utero to young adult stage, on locomotor skills and anxiety likebehavior among wistar rat. Four groups of female rats, bred with one non-pesticide exposed male, are used. On gestational day 6 , three groups receive daily, by intragastric gavage, 3 different doses of Malathion dissolved in corn oil (100, 200 and $300 \mathrm{mg} / \mathrm{kg}$ body weight). The control group receives the corn oil only. On postnatal day 21 , weaned offsprings are submitted to the similar treatment until adult age. Spontaneous locomotor activity is evaluated using the OpenField test (OF) and anxiety-like behavior is measured using both Open-Field (OF) test and Elevated Plus-Maze (EPM). Malathion at $300 \mathrm{mg} / \mathrm{kg}$ is toxic to pregnant dams, and pups are stillborns. In males, Malathionlevelat 100 and 200 $\mathrm{mg} / \mathrm{kg}$ induced significant impairment of spontaneous locomotor activities, which is reflected by high decrease of number of squares crossed in OF. In contrast, no discernible changes are observed within females Malathion-treated-group. However, females exposed to both malathion levels develop further anxiety-like response, expressed by significant reductions of exploratory activities in OF and time spent in open arm of EPM. Neurochemistry assay shows that cerebellum and neocortex acetylcholinesterase (AChE) activity inhibition are significantly increased with neurobehavioral deficits in males, relative to females. Overall, neurobehavioral outcomes of cur- rent study reveal that developmental exposure to Malathion induces sex-selective effects with greater changes in females.

Keywords: AChE Activity; Developmental Neurotoxicity; Malathion; Neurobehavior; Organophosphate Insecticides

\section{INTRODUCTION}

Organophosphate pesticides (OP) are widely used in agriculture pest control, in order to improve quality of human food. However, their general persistence in crops products and in environment is considered as hazardous for the public health $[1,2]$. The acute effects of people intoxication especially in suicides attempts, occupational accident case and food contamination are well studied in epidemiology [3]. The Malathion insecticide is one of the most used OP in United States and throughout the world. As evoked by Maroni et al.; Malathion is used inagriculture, veterinary practice and as ectoparasiticide applied against human body lice [4]. From chemical name [S-1, 2(bis-ethoxycarbonyl) ethylO, O-dimethyl phosphorodithioate]; Malathion inducesexcitotocixity effect through its bioactive form, malaoxon [5]. With respect to neurotoxicity mechanism, Malathion compounds exert commonly their primary effect by phosphorylating the serine residue at the active site of acetylcholinesterase (AChE). This leads to an inhibition of this enzyme in neural tissues, and so resulting overstimulation of cholinergic synapse in central and peripheral nervous system $[6,7]$. Although Malathion is considered as an OP relatively low acute toxicity, it could cause as others high toxic OPs, a great risk for human and environmental health. In California, Malathion was the third most frequently reported pesticide and caused five times more occupational 
illness than did the average pesticide [8]. In addition, Grether et al. examined occurrence of defects and low birth weight using newborn hospital discharge data and vital records in the San Francisco Bay area after aerial Malathion spraying [9]. Many biochemical and physiological effects of OP insecticide have been documented in man and animal [10]. It has been reported that subtoxic dose $\left(27 \mathrm{mg} / \mathrm{kg}, 1 / 50\right.$ of the $\mathrm{LD}_{50}$ for an oral dose $)$ of Malathion induced testicular toxicity by changes in sperm morphology, sperm mobility, testosterone level and histopathological of the testes, in sexually mature male rats [11]. Other study revealed that Malathion in subchronic exposure affects rat hepatic gluconeogenesis and glycogenolysis as well as inducing hyperglycemia [12]. Furthermore, the main target of OP insecticides remains the nervous system [13]. The acute OPs poisoning may lead to chronic sequelae including anxiety and depression [14], while long-term exposure may produce cognitive and neuropsychiatry disorders [15]. Brain effects of OPs, such as cognitive and neurobehavioral deficits and neurology diseases are occurred in agricultural workers-communities $[15,16]$. It has been suggested that long-term exposure to low-level of OP can interfere with normal development of central nervous system [17]. In fact, children are considered to be more vulnerable due to the significant anatomical and maturational changes occurring in the brain during developmental periods [18]. In animal model, previous study has shown that Malathion administered chronically for 28 days $(25-150 \mathrm{mg} /$ $\mathrm{kg}$ ) induced depression-like behavior in Forced Swimming Test [19]. Acker et al. [20] have also reported a decrease of motor coordination and muscular strength in rat pups exposed orally to Malathion, from post natal days (PND) 12 to 14. However, most developmental effects of OP studies are focused on high toxicity grade compounds such as Chlorpyrifos (CPF), Parathion (PTH) and Diazinon (DZN) $[21,22]$. Although the acute and subchronic physical effects of Malathion exposure are well documented $[23,24]$, there are a limited number of studies describing the neurobehavioral deficits caused by this OP.

The current study aims to investigate the effects of chronic exposure to subtoxique doses of Malathion, from in utero to young adult stage, on locomotor skills and anxiety like-behavior and on AChE activity in cerebellum and neocortex area in Wistar rats.

\section{MATERIALS AND METHODS}

\subsection{Chemical}

Malathion was obtained from commercial grade: Malyphos50 (active ingredients $500 \mathrm{~g}$ by liter). The Malathion concentration (50\% purity) in commercial grade was diluted in corn oil. Acetylthiocholine iodide, 5, 5- dithiobis-(2-nitrobenzoic acid) (DTNB) and others all chemicals were purchased from Sigma (USA).

\subsection{Animals and Treatment}

Twelve Wistar female rats, 4 months of age were obtained from a local breeding colony of Faculty of Sciences, Kenitra-Morocco. Rates were kept under standard condition, $12 \mathrm{~h} \mathrm{light} / 12$ dark cycle, $20^{\circ} \mathrm{C} \pm 2^{\circ} \mathrm{C}$ and $50 \%$ - 70\% humidity). They had access to commercial diet (ALF SAHEL-Casablanca, Morocco) and tap water ad libitum. After 2 weeks of acclimation, virgin rates and one-non-pesticide exposed male were bred in propylene cage covered by stainless steel mesh $(70 \times 40 \times 65 \mathrm{~cm})$. On gestational days six (GD 6), females were randomly divided in four groups of treatment. Then, three groups received by intragastric gavage incremental doses of Malathion insecticide dissolved in corn oil; 100, 200 and $300 \mathrm{mg} / \mathrm{kg}$ of body weight per day (Mal 100, Mal 200, Mal 300), and one control group (VEH) was given corn oil daily. Gestating females were treated from GD6 though post-partum day 21, rat pups were so exposed to Malathion via their mothers. On PND 21, weaned offsprings of each experimental group were submitted to similar dose regimens of preliminary protocol, and duration of treatment was extended to young adult stage. Experimental procedures are also examined and approved by the internal ethical committee for animal welfare.

\subsection{Physical Parameter Measurements}

Beginning on PND1, physical signs of toxicity and bodyweight were daily recorded during treatment.

\subsection{Behavioral Assessment}

\subsubsection{Open-Field Test (OF)}

To assess possible effects of Malathion on spontaneous locomotor activity and the ability to response to a novel environment rats were evaluated in open-field test during $10 \mathrm{~min}$. Apparatus consisted to top open wooden bow $(100 \times 100 \times 40)$ covered by a white consistent plastic. The floor of the arena were divided into 25 squares unit by black lines and lit in the center with halogen lamps of $60 \mathrm{~W}$ installed in the ceiling $[25,26]$. The frequencies of line crossing with the four paws (locomotion) and number of rearing in exploratory activity (anxiety level), were recorded by video camera positioned above the OF.

\subsubsection{Elevated Plus-Maze (EPM)}

To measure the degree of anxiety-related behavior, we use the elevated plus-maze. The apparatus is made of wood and consisted to two enclosed arm $(29 \times 5 \times 15)$ and two open arms $(29 \times 2.5 \times 15)$, placed at a right an- 
gle crossing in a common central platform $(5 \times 5)$. The central platform is illuminated with halogen lamps of 60 $\mathrm{W}$ offer rat an aversive condition spatial. Each animal is placed onto platform facing the open arm and the following behaviors are recorded during $5 \mathrm{~min}$. The time spent in each arm and the numbers of entries in open and close arm are scored from video sequence. The level anxiety of rat is assessed by the time spent on the open arm divided by total time, and the number of open-arm entries divided by total number of arm entries [27].

\subsection{AChE Activity Assay}

Rats are killed by decapitation $24 \mathrm{~h}$ after behavioral tests. Samples of brain correspondent to cerebellum and neocortex areas are removed and homogenized in buffer Tris/ $\mathrm{HCl}\left(50 \mathrm{mmol} \cdot \mathrm{L}^{-1}, \mathrm{pH}\right.$ 7.3) and Sucrose (0.32 $\left.\mathrm{mol} \cdot \mathrm{L}^{-1}\right)$. The homogenate is centrifuged at $1000 \times \mathrm{g}$ for $15 \mathrm{~min}$ at $4^{\circ} \mathrm{C}$. AChE activity is assayed according to Elman method [28], using acetylthiocholine iodide as a substrate. Reaction mixture contained $100 \mu \mathrm{L}$ of supernatant, $4 \mu \mathrm{L}$ of substrate $(75 \mathrm{mM}), 150 \mu \mathrm{L}$ of Dithiobisnitrobenzoic acid (DTNB Elman's reagent, $100 \mathrm{Mm}$ ) and 3 . $0 \mathrm{ml}$ of phosphate buffer $(\mathrm{pH} \mathrm{8.0)}$. The rate of Acetylthiocholine iodide hydrolysis is measured at $412 \mathrm{~nm}$ in spectrophotometer for $10 \mathrm{~min}$. Brain AChE is expresses in percent of inhibition from control group [29].

\subsection{Statistical Analysis}

All data are expressed as means \pm S.E.M (Standard Error of Mean). Repeat measured and one-way analyses of variance (ANOVA) are used to analyze difference on body weight and behavioral scores respectively between groups. Post hoc comparisons are made using Tukey's HDS test, when appropriate. Two-way ANOVA (sex $\times$ treatment) interaction is used to explain behavioral performances. Statistical significant is assumed at $\mathrm{p}<0.05$.

\section{RESULTS}

\subsection{General Physical Observations}

Malathion exposure at dosage $300 \mathrm{mg} / \mathrm{kg}$ (b.w) induced toxicity to pregnant dams; all offspring are stillborns during parturition. In others' treated groups, no sign of toxicity such as body tremor, salivation, weakness and convulsion are observed. Repeated measure ANOVA shows a significant difference in body weight, with inmale rats $(p=0.02)$. Turkey post-hoc analysis revealed that body weight loss is significantly important $(\mathrm{p}<0.001)$ in both treated-groups; "Mal 100" and "Mal 200"compared to VEH. But no difference is observed between them. The same observation has been found in female group (data not shown).

\subsection{Open-Field Behavior}

Malathion altered significantly spontaneous locomotion activity, in both sexes (Figure 1(a)). In males, oneway ANOVA shows significant reduction in number of square crossed between treated groups $[F(5,38)=33.95$; $\mathrm{p}<0.001]$. Tukey's post-hoc reveals Malathion induced high spontaneous locomotor function changes in Mal 200 group ( $\mathrm{p}<0.001)$ and in Mal 100 group $(\mathrm{P}=0.002)$, compared to VEH. In females, no difference in mean of number of square crossed is observed between both Malathion treated-group; Mal 100 and Mal 20. But, turkey post-hoc shows a high significant alteration of locomotor activity $(\mathrm{p}<0.001)$, when compared to $\mathrm{VEH}$ females. Indeed, the sex $\times$ treatment analysis revealed that locomotor activity is significantly decreased in females Malathion-treated $(\mathrm{p}=0.008)$, relative to Males. As depicted in Figure 1(b) and shown by Turkey posthoc test, in males, Malathion at both doses (100 and 200 $\mathrm{mg} / \mathrm{kg}$ ) produce significant changes in number of rearing $[\mathrm{F}(5,38)=21.41, \mathrm{p}<0.001]$. In females, Mal 200 and Mal 100 group performed slowly in number of rearing $(\mathrm{p}$ $=0.001)$, relative to $\mathrm{VEH}$ female. However, sex $\times$ treatment interaction showed that females presented significant alteration of anxiety level (reduction exploratory activity), than males $[\mathrm{F}(5,38)=5.54 ; \mathrm{p}=0.01]$.

\subsection{Anxiety-Like Behaviors Assessment}

The rats' behavior in EPM shows that Malathion exposure at both doses (100 and $200 \mathrm{mg} / \mathrm{kg}$ ) induces anxiety-like response (Figure 2). In males, one way ANOVA indicates a significant difference in percentage of times spent in open arm $[F(5,38)=61.05 ; p<0.001]$. Turkey's post hoc analysis confirms a decrease of open arm time in Mal $200(\mathrm{p}<0.001)$ and Mal $100(\mathrm{p}=0.001)$, compared to VEH. In females, one-way ANOVA showed that any doses of Malathion induce anxiety-like behavior $(\mathrm{p}<0.001)$. Post-hoc analysis revealed high reduction of time spent in open arm of EPM in Malathion-treated; Mal 200 group $(p<0.001)$ and Mal 100 group $(p=0.03)$, relative to VEH females (Figure 2(a)). Moreover, the frequency of entries into open arm is significantly altered in both sexes treated with Malathion $(\mathrm{p}<0.001)$, when compared to VEH. But Turkey post-hoc test showed that, in both sexes, Mal 200 group exhibits more anxiety likebehavior than Mal 100 group rats (Figure 2(b)).

The last parameter to measure anxiety level is number of entries into enclosed arm of EPM. In males, one-way ANOVA shows the total number of entries into enclosed arm is elevated in Malathion-treated ( $p=0.013$ ), compared to VEH group. But, a simple difference in number of entries into enclosed arm is observed between Mal 100 and Mal 200 group ( $p<0.01)$. In females, Malathion anxiogenic effect is more expressed in treated groups 


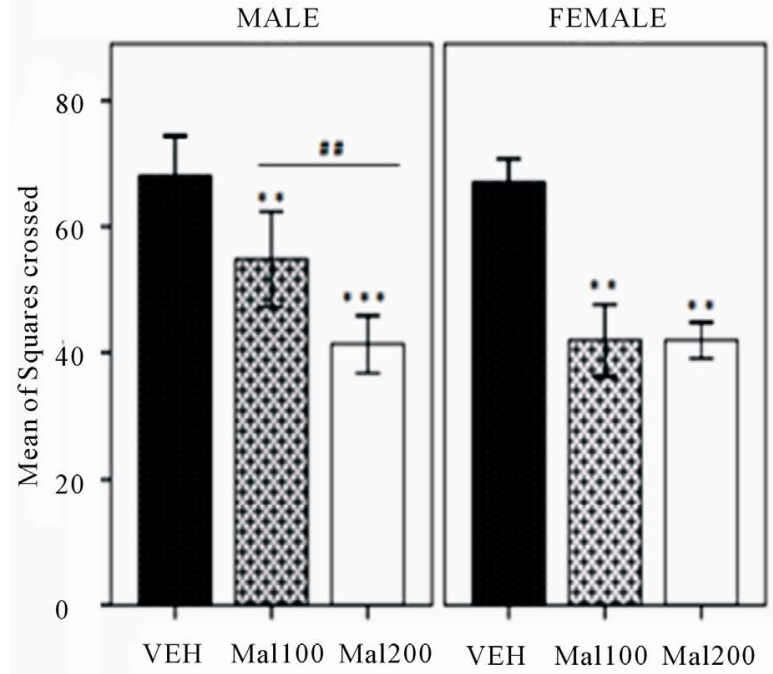

(a)

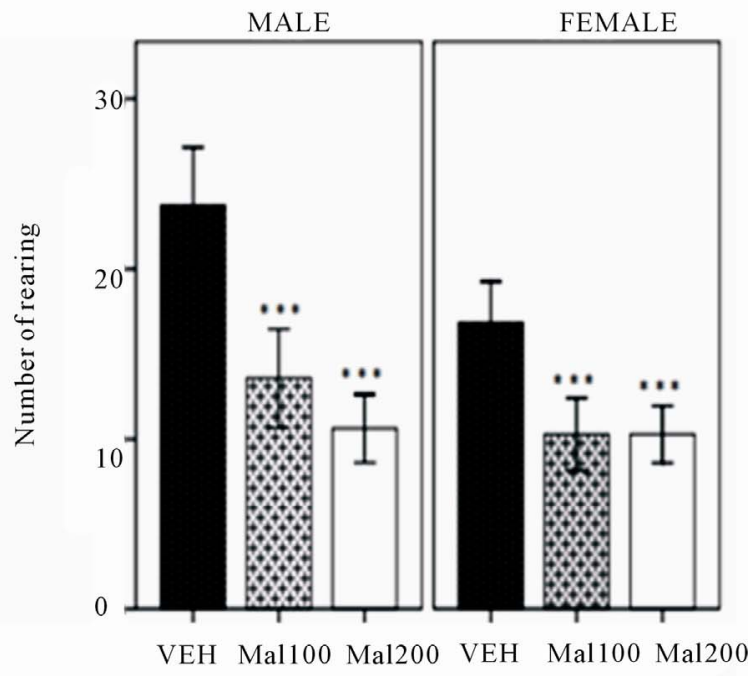

(b)

Figure 1. Effectsof developmental exposure to Malathion in Open-field test. (Mal 100 and Mal 200 represent 100 and $200 \mathrm{mg} / \mathrm{kg}$; p.o, respectively). (a) Spontaneous locomotor activity expressed in Number of square crossed. (b) Exploratory activity expressed in Number of rearing. Data expressed as Mean \pm S.E.M of $7-8$ animals per group. ${ }^{* *} \mathrm{p}<0.01$ and ${ }^{* * *} \mathrm{p}<0.001$ ascompared to VEH; ${ }^{\# \#} \mathrm{p}<0.01$ as comparison between Mal 100 and Mal 200 groups (One-Way ANOVA/ Tukey's post-hoc analysis).

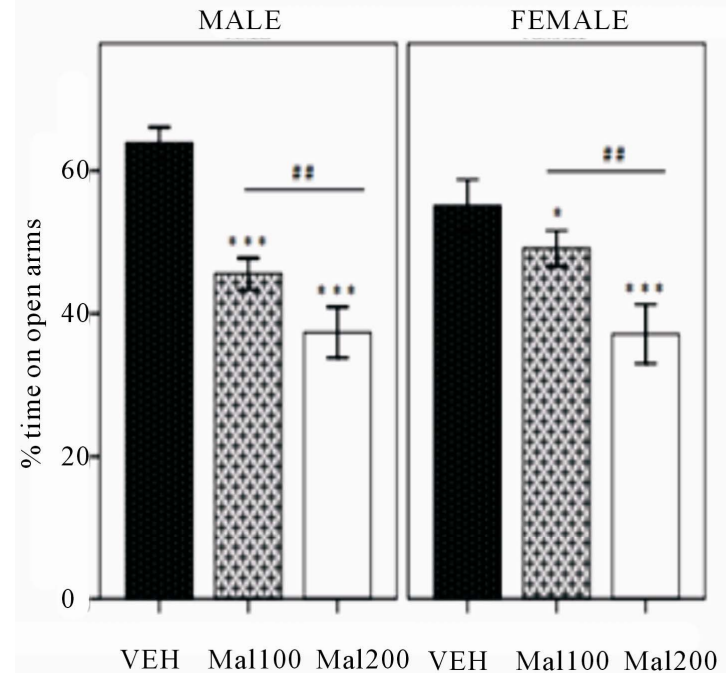

(a)

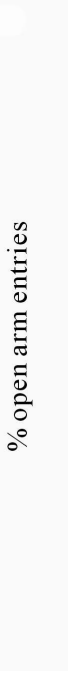

Figure 2. Effect of Malathion exposure on anxiety-like behavior in Elevated Plus-Maze (Mal 100 and Mal 200 represent 100 and $200 \mathrm{mg} / \mathrm{kg}$; p.o, respectively). (a) percentage of time spent into open arms. (b) percentage of open-arm entries. Data expressed as Mean \pm S.E.M of $7-8$ animals per group. ${ }^{* *} \mathrm{p}<0.01$ and ${ }^{* * *} \mathrm{p}<0.001$ as compared to VEH; ${ }^{\# \#} \mathrm{p}<0.01$ and ${ }^{\# \# \#} \mathrm{p}$ $<0.001$ as comparison between Mal 100 and Mal 200 groups (One-Way ANOVA/ Tukey's post-hoc analysis).

though greater number of entries into enclosed arm than non-exposed VEH $(p<0.001)$ (Figure 3). Overall, sex $\times$ treatment reveals that anxiety level alteration is significantly pronounced in females $(\mathrm{p}<0.001)$.

\subsection{AChE Activity Assays}

In Males group, developmental exposure at dose 100 and $200 \mathrm{mg} / \mathrm{kg}$ increased significantly cortex AChE ac-

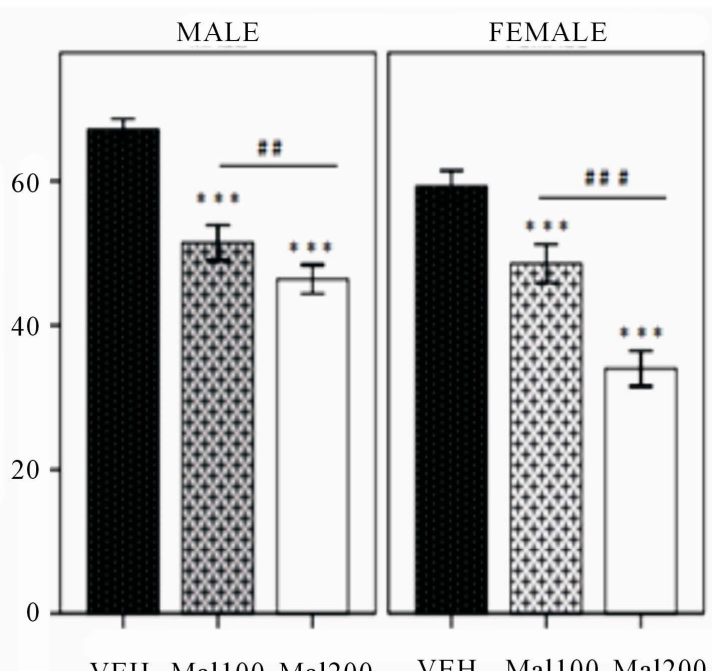

tivity inhibition; $+20 \%(\mathrm{p}<0.001)$ and $+36 \%(\mathrm{p}<$ $0.0001)$, respectively. Turkey post hoc analysis detects that there is statistically also high difference between Mal 100 and Mal 200 groups $(\mathrm{p}<0.001)$. In contrast, within females group, no significant variation of $\mathrm{AChE}$ inhibition is observed (Figure 4).

We investigate also AChE activity in cerebellum area. One-way ANOVA analysis shows that in males, the pattern of AChE activity inhibition to both dose 100 and 


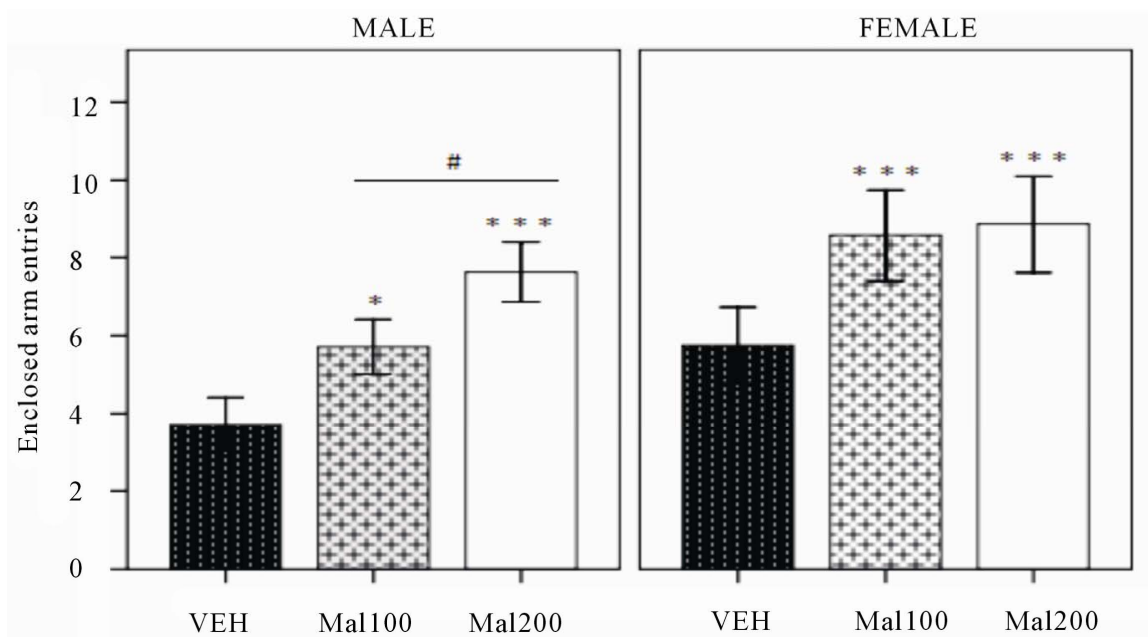

Figure 3. Effect of Malathion exposure on anxiety-like behavior (Mal100 and Mal 200 represent100 and $200 \mathrm{mg} / \mathrm{kg}$; p.o, respectively). Data expressed number of enclosed arm entries in Elevated Plus-Maze test (Mean \pm S.E.M of $7-8$ animals per group). ${ }^{*} \mathrm{p}<0.05$ and ${ }^{* * *} \mathrm{p}<0.001$ as compared to VEH; ${ }^{\#}<0.05$ as comparison between Mal 100 and Mal 200 groups (One-Way ANOVA/Tukey’s post-hoc analysis).

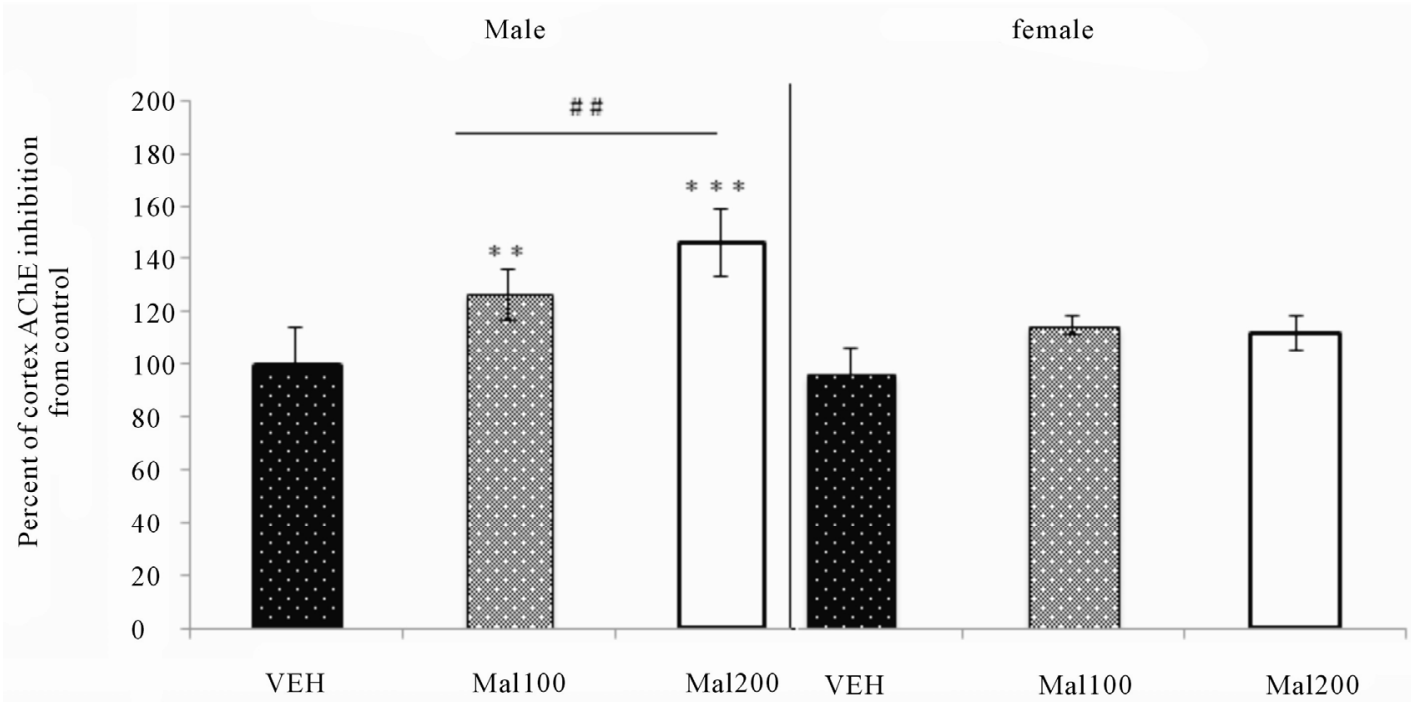

Figure 4. Effect of Malathion exposure on neocortex AchE activity (Mal100 and Mal200 group receive 100 and $200 \mathrm{mg} / \mathrm{kg}$; p.o, respectively).Data expressed percent of AChE change from VEH (Mean \pm S.E.M of 7 - 8 animals per sex's group). ${ }^{* *} \mathrm{p}<0.01$ and ${ }^{* * *} \mathrm{p}<0.001$ as compared to $\mathrm{VEH} ;{ }^{\#} \mathrm{p}<0.01$ as comparison between Mal 100 and Mal 200 groups (One-Way ANOVA/Tukey's post-hoc analysis).

$200 \mathrm{mg} / \mathrm{kg}$ is approximately similar, but significant difference is observed compared to control $(p<0.001)$. In females groups, studied levels of Malathion exposure don't induce any significant change in AChE inhibition $(\mathrm{p}>0.05)$ (Figure 5).

\section{DISCUSSION}

The current study reported that different Malathion concentrations don't have any physical signs as weakness, tremor, and convulsion. But, Malathion exposure has significantly affected body weight of both sexes.
This result is consistent with previous past study showing that subchronic exposure to Chlorpyrifos (CPF), a high toxic OP, reduced significantly body weight [30]. It could be due to cholinergic overstimulation that causes increase of gastric motility and reduction in absorption [31]. However, no weight loss was observed in rat pups (PND 12 - 14), when they were exposed orally for four consecutive days to similar doses of Malathion as our [20]. These observations suggest that Malathion effects are not only related to dose-response and toxicity grade, but duration and period of exposition can be major factor to explain this deficit. 


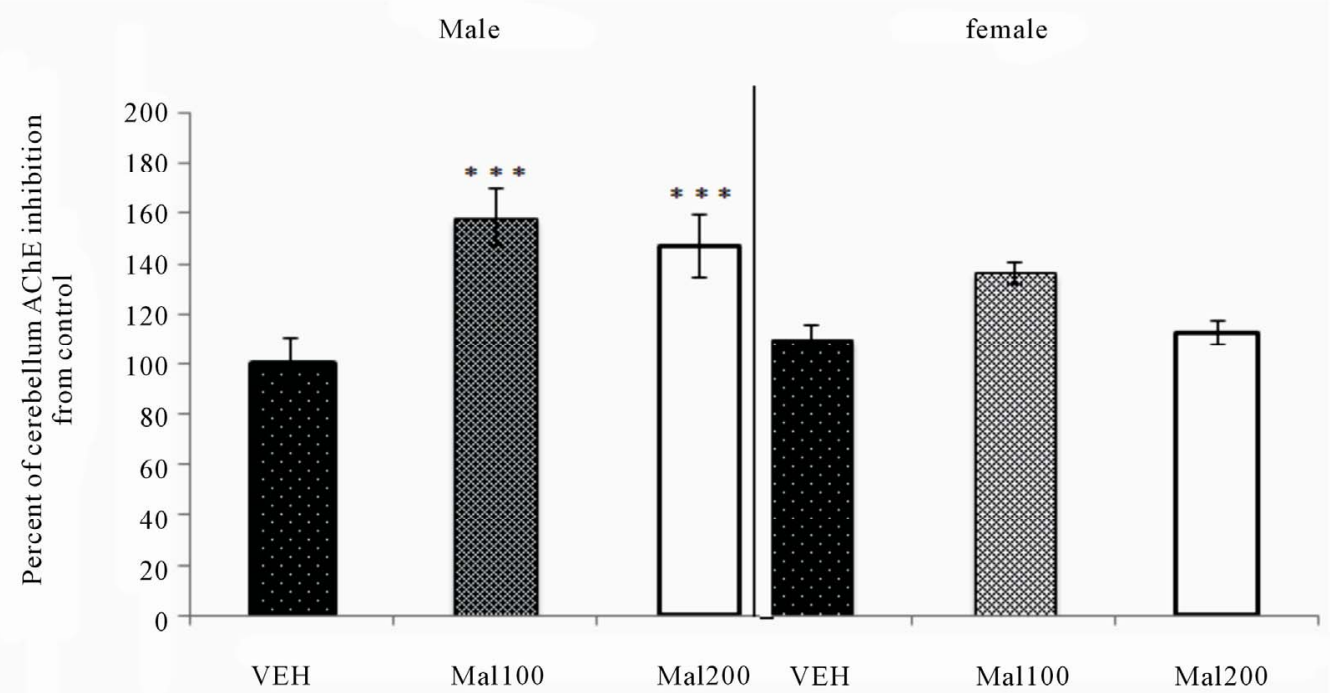

Figure 5. Effect of Malathion exposure on cerebellum AchE activity (Mal100 and Mal200 group receive 100 and $200 \mathrm{mg} / \mathrm{kg}$; p.o, respectively). Data expressed percent of AChE change from VEH (Mean \pm S.E.M of 7 - 8 animals per sex's group). ${ }^{* * *} \mathrm{p}<0.001$ as compared to VEH (One-Way ANOVA/Tukey's post-hoc analysis).

Furthermore, Current study demonstrates that developmental exposure to Malathion decreases significantly locomotor activity of both sexes, at young adult stage. The dose of $100 \mathrm{mg} / \mathrm{kg}$ decreases the number of square crossed in OF. Malathion at $200 \mathrm{mg} / \mathrm{kg}$ affects further male rats, but no discernible motor behavioral changes in females treated. This effect is accompanied by great changes in exploratory activities, as evidence by significant reduction of number of rearing in the OF. In fact, the reduction of number of square crossed and number of rearing are positively correlated to deficits in arousal, an increase in emotional response or motor activity impairments [32]. Previous study reported that also rats prenatally exposed to CPF present significant alteration of spontaneous locomotion activity, that are followed by a general hypoactivity in both sexes when exposition is done at middle of gestational phase [33]. However, recent study point out rat pups (PND 12 - 14) exposed to Malathion for 4 days presented no changes of spontaneous locomotor and exploratory activities in OF test [20]. This suggests that developmental exposure to Malathion lead to delayed abnormal locomotor behavior by disrupt developmental processes in the brain. In fact, during gestational phase (GD 10 - 16) in rats, motor area corresponding to fetus's posterior brain in development: brainstem, midbrain, cerebellum, spinal cords, are firstly distinguished, followed by anterior structure like neocortex and hippocampus [34]. In this critical period, brain developmental program is highly sensitive to OP insecticide with a later neurology and neurobehavioral alteration [35,36].

Beside, in Malathion treated-groups, the rate of $\mathrm{AChE}$ activity inhibition in neocortex is highly elevated in males, but no significant changes in females. The same variation is observed in cerebellum cortex. Similar to ours outcomes, others studies found that subtoxic dose of Malathion induced AChE inhibition more than 20\% [5, 37]. In others words, developmental exposure to OPs including Malathion lead to persistence deficiencies in cholinergic synaptic at adulthood, as evidenced Slotkin et al. [21]. During brain development, acetylcholine and cholinergic projection play major roles in proliferation, migration and synaptogenesis and in the development of normal neural cytoarchitecture [38]. So, cholinergic transmission disrupted subsequently to AChE inhibition, might be a factor of developmental neurotoxicity, including motor development or motor coordination deficits [19]. Our study revealed also developmental exposure to Malathion induced sex-selective alteration in spontaneous locomotor and anxiety level in OF test. Female scored poorly than males. But, neurobehaviour deficits are not correlated to AChE activity inhibition. This paradox could probably due to other neurochemistry mechanism in locomotor behavior alteration. As state in past study, OPs exposure at subtoxic dose of AChE inhibition can alter the dopaminergic system, a regulator of locomotion activities $[39,40]$.

We used E. P. M to confirm deficits in emotional responsiveness evidenced in OF test. Originally, this test has been an ethologically valid animal's model of human anxiety [41]. In our knowledge, no study has investigated on anxiety effect of developmental exposure to Malathion. Neurobehavioral data of current study showed an anxiogenic-like response in animals developmentally ex- 
posed to Malathion. A significant reduction of time spent and number of entries into open arm of EPM are observed in treated-groups. Some epidemiological and toxicological studies are evidenced relationship between OP compounds and increase in prevalence of the human brain development alteration; clinical symptoms include mental delay, anxiety, and neurobehavioral abnormalities in young children living in agricultural communities [16, 42]. The current animal model investigation demonstrates that critical period of brain development (i.e. from in utero to adolescence) remains sensitive to anxiogenic effects of Malathion. In contrast, intraperitoneal subacute exposure to malathion dosage ranging from 25 to 150 $\mathrm{mg} / \mathrm{kg}$, in adult rats, did shown neither alteration of anxiety level after assessment in EPM [43]. As state in previous study, in rats, perinatal period correspondent to last days of gestation and post-natal life (PND 1-4) [44], in later (PND 11-14) [45] was revealed as sensitive period in which OP can disrupt anxiety level. Our observations confirm the paradigm that, despite low toxic property, Malathion intoxication is more injurious to embryonic brain and behavior sequel caused early, can be observed in the adult. In addition, detoxification abilities were deficiencies because of liver or kidney OPs enzymes immaturities in fetus and rat pups, relative to adults [46].

To elucidate the anxiogenic-like behavior effects, it is most important to know the mechanisms triggered by Malathion. As mentioned above, developmental exposure to Malathion leads to significant irreversible AChE inhibition, later at young adult stage. That is followed by a prolonged overstimulation of nicotinic cholinergic receptor. Alteration at the cholinergic synaptic transmission supports strongly the hypothesis of anxiogenic effect induced by Malathion. Indeed, past studies have demonstrated that cholinergic system plays a modulatory role in the control of anxiety level $[47,48]$. Current revealed that all dose regimens of Malathion induced anxiogenic effects in both sexes, but females were significantly affected. Moreover, as mentioned above, a weak relationship links Malathion exposure and AChE activeties disruption in females. It is still unclear to explain this paradox. That can be possible due to interaction between Malathion and estrogenic activity disruption in brain sexual differentiation. However, the common effects of organophosphate insecticides on serotoninergic system can be a main explanation of high level of anxiety expressed in females [49].

In conclusion, current study demonstrated that chronic exposure of rats to subtoxic doses of Malathion during critical phase of brain development induced later neurobehaviour impairments. Although, effects of Malathion are significantly pronounced in females, exact neurochemistry mechanisms remain unclear. Moreover, immunohistological study in cerebellum and cerebral cortex of rats exposed can further contributed to elucidate these disorders.

\section{ACKNOWLEDGEMENTS}

This study was supported byGDRI Neuro and N£uromed consortium. mailto: ahami40@yahoo. fr.

\section{REFERENCES}

[1] Dallegrave, E., Mantese, F.D., Oliveira, R.T., Andrade, A.J.M., Dalsenter, P.R. and Langeloh, A. (2007) Pre- and postnatal toxicity of the commercial glyphosate formulation in Wistar rats. Archives of Toxicology, 81, 665-673. doi:10.1007/s00204-006-0170-5

[2] Yen, J.H., Lin, K.H. and Wang, Y.S. (2000) Potential of the insecticides acephate and methamidophos to contaminate groundwater. Ecotoxicology and Environmental Safety, 45, 79-86. doi:10.1006/eesa.1999.1846

[3] Baldi, I., Brochard, P., Mohammed-Brahim, B., Rolland, P. and Salamon, R. (1999) Méthodes d'estimation rétrospective de l'exposition professionnelle aux pesticides. Revue d'Epidémiologie et de Santé Publique, 47, 165-174.

[4] Maroni, M., Colosio, C., Ferioli, A. and Fait, A. (2000) Biological monitoring of pesticide exposure: A review. Toxicology, 7, 1-118.

[5] Hazarika, A., Sarkar, S.N., Hajare, S., Kataria, M. and Malik, J.K. (2003) Influence of malathion pretreatment on the toxicity of anilofos in male rats: A biochemical interaction study. Toxicology, 185, 1-8. doi:10.1016/S0300-483X(02)00574-7

[6] Wang, L.M., Ye, W.H., Zhou, S.S., Lin, K.D., Zhao, M.R. and Liu, W.P. (2009) Acute and chronic toxicity of organophosphate monocrotophos to Daphnia magna. Journal of Environmental Science and Health, Part B, 44, 3843.

[7] Kwong, T.C. (2002) Organophosphate pesticides: Biochemistry and clinical toxicology. Therapeutic Drug Monitoring, 24, 144-149. doi:10.1097/00007691-200202000-00022

[8] Brenner, L. (1992) Malathion. Journal of Pesticide Reform, 12, 29.

[9] Grether, J.K., Harris, J.A., Neutra, R., et al. (1987) Exposure to aerial malathion application and the occurrence of congenital anomalies and low birthweight. American Journal of Public Health, 77, 1009-1010. doi:10.2105/AJPH.77.8.1009

[10] Engel, A.G., Lambert, E.H. and Santa, T. (1973) Neurology (Minneap.) 23, 1273-1281.

[11] Uzun, F.G., Kalender, S., Durak, D., Demir, F. and Kalender, Y. (2009) Malathion-induced testicular toxicity in male rats and the protective effect of vitamins $\mathrm{C}$ and $\mathrm{E}$. Food and Chemical Toxicology, 47, 1903-1908. doi:10.1016/j.fct.2009.05.001

[12] Abdollahi, M., Donyavi, M., Pournourmohammadi, Sh. and Saadat, M. (2004) Hyperglycemia associated with increased hepatic glycogen phosphorylase and phosphoenolpyruvatecarboxykinase activities in rats following sub- 
chronic exposure to Malathion. Comparative Biochemistry and Physiology Part C: Toxicology \& Pharmacology, 137, 343-347. doi:10.1016/j.cca.2004.03.009

[13] Abou-Donia, M.B. (2003) Organophosphorus ester-induced chronic neurotoxicity. Archives of Environmental Health, 58, 484-497. doi:10.3200/AEOH.58.8.484-497

[14] Stallones, L. and Beseler, C. (2002) Pesticide illness, farm practices, and neurological symptoms among farm residents in Colorado. Environmental Research, 90, 8997. doi:10.1006/enrs.2002.4398

[15] Salvi, R.S., Lara, D.R., Ghisol, E.S., Portela, L.V., Dias, R.D. and Souza, D.O. (2003) Neuropsychiatric evaluation in subjects chronically exposed to organophosphate. Toxicological Sciences, 72, 267. doi:10.1093/toxsci/kfg034

[16] Ruckart, P.Z., Kakolewski, K., Bove, F.J. and Kaye, W.E. (2004) Long-term neurobehavioral health effects of methyl parathion exposure in children in Mississippi and Ohio. Environmental Health Perspectives, 112, 46-51. doi:10.1289/ehp.6430

[17] Slotkin, T.A. (1999) Developmental cholinotoxicants: Nicotine and chlorpyrifos. Environ. Environmental Health Perspectives, 107, 71-80.

[18] Andersen, S.L. (2003) Trajectories of brain development: Point of vulnerability or window of opportunity. Neuroscience \& Biobehavioral Reviews, 27, 3-18. doi:10.1016/S0149-7634(03)00005-8

[19] Ramos, Z.R., Fortunato, J.J., Agostinho, F.R., Martins, M.R., Correa, M., Schetinger, M.R., Dal-Pizzol, F. and Quevedo, J. (2006) Influence of malathion on acetylcholinesterase activity in rats submitted to a forced swimming test. Neurotoxicity Research, 9, 285-290. doi:10.1007/BF03033318

[20] Acker, C.I., Souza, A.C., Pinton, S., da Rocha, J.T., Friggi, C.A., Zanella, R. and Nogueira C.W. (2011) Repeated Malathion exposure induces behavioral impairment and AChE activity inhibition in brains of rat pups. Ecotoxicology and Environmental Safety, 74, 2310-2315. doi:10.1016/i.ecoenv.2011.07.035

[21] Slotkin, T.A., Cousins, M.M., Tate, C.A. and Seidler, F.J. (2001) Persistent cholinergic presynaptic deficits after neonatal chlorpyrifos exposure. Brain Research, 902, 229243. doi:10.1016/S0006-8993(01)02387-3

[22] Slotkin, T.A., Bodwell, B.E., Levin, E.D. and Seidler, F.J. (2008) Neonatal exposure to low doses of diazinon: Longterm effects on neural cell development and acetylcholine systems. Environmental Health Perspectives, 116, 340348. doi:10.1289/ehp.11005

[23] Lal, C.S., Kumar, V., Ranjan, A., Das, V.N., Kumar, N., Kishore, K. and Bhattacharya, S.K. (2004) Evaluation of cholinesterase level in an endemic population exposed to Malathion suspension formulation as a vector control measure. Memórias do Instituto Oswaldo Cruz, 99, 219. doi:10.1590/S0074-02762004000200018

[24] Lee, P. and Tai, D.Y. (2001) Clinical features of patients with acute organophosphate poisoning requiring intensive care. Intensive Care Medicine, 27, 694. doi:10.1007/s001340100895

[25] Azzaoui, F.Z., Ahami A.O.T. and Khadmaoui A. (2008)
Impact of aluminum sub-chronic toxicity on body weight and recognition memory of wistar rat. Pakistan Journal of Biological Sciences, 11, 1830-1834. doi:10.3923/pjbs.2008.1830.1834

[26] Azzaoui, F.Z., Ahami A.O.T. and Khadmaoui A. (2009) Impact of lead sub-chronic toxicity on recognition memory and motor activity of Wistar rat. Pak. Pakistan Journal of Biological Sciences, 12, 173-177. doi:10.3923/pjbs.2009.173.177

[27] Carobrez, A.P. andBertoglio, L.J. (2005) Ethological and temporal analyses of anxiety) like ehavior: Elevated plusmaze model 20 years on. Neuroscience \& Biobehavioral Reviews, 29, 1193-1205.

doi:10.1016/j.neubiorev.2005.04.017

[28] Ellman, G.L., Courtney, K.D., Andres, V.R.M. and Featherstone, R.M. (1961) A new and rapid colorimetric determination of acetylcholinesterase activity. Biochemical Pharmacology, 7, 88-95. doi:10.1016/0006-2952(61)90145-9

[29] Azzaoui, F.-Z., Hami, H., El-Hioui, M., Boulbaroud, S. and Ahami, A. (2012) Attempt at the determination of aluminum nitrate LD50 and the study of its neurotoxincological effect in Wistar rat. Biology and Medicine, 4, 89-94

[30] Lim, K.L., Tay, A., Nadarajah, V.D. and Mitra, N.K. (2011) The effect of consequent exposure of stress and dermal application of low doses of chlorpyrifos on the expression of glial fibrillary acidic protein in the hippocampus of adult mice. Journal of Occupational Medicine and Toxicology, 6, 4.

[31] Jones, A.L. and Karalliedde, L. (2006) Poisoning. In: Boon, N.A., Colledge, N.R., Davidson, S.S. and Walker, B.R., Eds., Davidson's Principles and Practice of Medicine, 20th Edition, Churchill Livingstone, Edinburgh, 203-226.

[32] Prut, L. and Belzung, C. (2003) The open field as a paradigm to measure the effects of drugs on anxiety-like behaviors: A review. European Journal of Pharmacology, 463, 3-33. doi:10.1016/S0014-2999(03)01272-X

[33] Icenogle, L.M., Christopher, N.C., Blackwelder, W.P., Caldwell, D.P., Qiao, D., Seidler, F.J., Slotkin, T.A. and Levin, E.D. (2004) Behavioral alterations in adolescent and adult rats caused by a brief subtoxic exposure to chlorpyrifos during neurulation. Neurotoxicology and Teratology, 26, 95-101. doi:10.1016/i.ntt.2003.09.001

[34] Rice, D. and Barone Jr., S. (2000) Critical periods of vulnerability for the developing nervous system: Evidence from humans and animal models. Environmental Health Perspectives, 108, 511-533.

[35] Costa, L.G., Aschner, M., Vitalone, A., Syversen, T. and Soldin, O.P. (2004) Developmental neuropathology of environmental agents. Annual Review of Pharmacology and Toxicology, 44, 87-110. doi:10.1146/annurev.pharmtox.44.101802.121424

[36] Eskenazi, B., Bradman, A. and Castorina, R. (1999) Exposures of children to organophosphate pesticides and their potential adverse health effects. Environmental Health Perspectives, 107, 409-419. doi:10.1289/ehp.99107s3409

[37] Assini, F.L., Zanette, K.D., Brocardo, P.S., Pandolfo, P., Rodrigues, A.L. and Takahashi, R.N. (2005) Behavioral 
effects and ChE measures after acute and repeated administration of malathion in rats. Environmental Toxicology and Pharmacology, 20, 443-449. doi:10.1016/j.etap.2005.05.007

[38] Hohmann, C.F. (2003) A morphogenetic role for acetylcholine in mouse cerebral neocortex. Neuroscience \& Biobehavioral Reviews, 27, 351-363. doi:10.1016/S0149-7634(03)00066-6

[39] Aldridge, J.E., Meyer, A., Seidler, F.J. and Slotkin, T.A. (2005) Alterations in central nervous system serotonergic and dopaminergic synaptic activity in adulthood after prenatal or neonatal chlorpyrifos exposure. Environmental Health Perspectives, 113, 1027-1031. doi:10.1289/ehp.7968

[40] Cory-Slechta, D.A. (1995) Relationships between leadinduced learning impairment and changes in dopaminergic, cholinergic and glutamatergic neurotransmitter system function. Annual Review of Pharmacology and Toxicology, 35, 391-415. doi:10.1146/annurev.pa.35.040195.002135

[41] Dawson, G.R. and Tricklebank, M.D. (1995) Use of the elevated plus-maze in the search for novel anxiolytic agents. Trends in Pharmacological Sciences, 16-33.

[42] Eskenazi, B., Rosas, L.G., Marks, A.R., Bradman, A., Harley, K., Holland, N., Johnson, C., Fenster, L. and Barr, D.B. (2008) Pesticide toxicity and the developing brain. Basic \& Clinical Pharmacology \& Toxicology, 102, 228236. doi:10.1111/j.1742-7843.2007.00171.x

[43] Valvassori, S.S., Fortunato, J.J., Gomes, K.M., Réus, G.Z., Martins, M.R., Gavioli, E.C., Schetinger, M.R., Dal-Pizzol, F. and Quevedo, J. (2007) Acute and subacute exposure to malathion impairs aversive but not non-associative memory in rats. Neurotoxicity Research, 12, 71-79. doi:10.1007/BF03033902
[44] Aldridge, J.E., Levin, E.D., Seidler, F.J. and Slotkin, T.A. (2005) Developmental exposure of rats to chlorpyrifos leads to behavioral alterations in adulthood, involving serotonergic mechanisms and resembling animal models of depression. Environmental Health Perspectives, 113, 527-531. doi:10.1289/ehp.7867

[45] Ricceri, L., Venerosi, A., Capone, F., Cometa, M.F., Lorenzini, P., Fortuna, S. and Calamandrei, G. (2006) Developmental neurotoxicity of organophosphorus pesticides: Fetal and neonatal exposure to chlorpyrifos alters sex-specific behaviors at adulthood in mice. Toxicological Sciences, 93, 105-113. doi:10.1093/toxsci/kf1032

[46] Johnson, T.N. (2003) The development of drug metabolising enzymes and their influence on the susceptibility to adverse drug reactions in children. Toxicology, 192, 37-48. doi:10.1016/S0300-483X(03)00249-X

[47] Ouagazzal, A.M., Kenny, P.J. and File, S.E. (1999) Modulation of behavior on trials 1 and 2 in the elevated plusmaze test of anxiety after systemic and hippocampus administration of nicotine. Psychopharmacology, 144, 5460. doi:10.1007/s002130050976

[48] File, S.E., Gonzalez, L.E. and Andrews, N. (1998) Endogenous acetylcholine in the dorsal hippocampus reduces anxiety through actions on nicotinic and muscarinic1 receptors. Behavioral Neuroscience, 112, 352-359. doi:10.1037/0735-7044.112.2.352

[49] Slotkin, T.A., Tate, C.A., Ryde, I.T., Levin, E.D. and Seidler, F.J. (2006) Organophosphate insecticides target the serotonergic system in developing rat brain regions: Disparate effects of diazinon and parathion at doses spanning the threshold for cholinesterase inhibition. Environmental Health Perspectives, 114, 1542-1546. doi:10.1289/ehp.9337 